\title{
Reunião de articulação de trabalhos conjuntos entre Brasil-Argentina sobre uso e conservação de recursos genéticos vegetais ornamentais
}

\author{
"Taller de Articulación de Trabajos Conjuntos entre Brasil-Argentina sobre el uso \\ y la conservaciòn de Recursos Genéticos Vegetales Ornamentales"
}

Período: 09 a 12 de dezembro de 2008.

Local: Instituto de Floricultura (INTA - Castelar), Buenos Aires-Argentina.

Participantes: Dr. Alejandro S. Escandón (INTA), Eng. Agr. (M.Sci) Laura Bullrich (INTA), Dra. Gabriela Facciuto (INTA), Dra. Ana Cecília R. de Castro (EMBRAPA-CNPAT), Dra. Vivian Loges (UFRPE), Dr. Antonio Fernando C. Tombolato (IAC), Eng. Agr. Daniel Morisigue (INTA), Eng. Agr. Marcelo Ferrer (INTA) e bolsistas do Instituto de Floricultura del INTA.

Esta reunião foi motivada a partir de contatos realizados para elaboração do Projeto "Rede de Recursos Fitogenéticos Ornamentais da América do Sul" em resposta ao edital PROSUL (CNPq No 011/2008). O objetivo foi promover a interação e a integração de pesquisadores e projetos de interesse comum para formação de uma rede de referência de uso e manutenção de recursos genéticos de espécies vegetais ornamentais entre o Brasil e a Argentina, podendo se expandir futuramente a América do Sul, que venha fortalecer e elevar as competências regionais dos grupos envolvidos e promover o uso racional e sustentável dos recursos fitogenéticos ornamentais.

Durante a reunião, foram apresentados os projetos em andamento e as principais atividades com floricultura desenvolvidas em suas instituições. Foram discutidos formas de ampliar a integração entre Brasil e Argentina.

\section{RELEVÂNCIADO TEMA}

A Floricultura, atividade econômica que envolve a produção de flores de corte, vasos e jardinagem, é uma alternativa viável, técnica e economicamente, para a geração de emprego e renda em toda a América Latina pela existência de clima e solos apropriados para o cultivo das espécies comercializadas nos principais mercados do mundo. Além de movimentar cifras milionárias, possibilita retorno econômico relativamente rápido em pequenas áreas e cria muitos postos de trabalho para ambos os sexos, contribuindo para a fixação das famílias no campo e ocupação das áreas com aptidão agrícola no entorno das grandes cidades, situação desejável para o toda a América Latina.

A atividade é motivada por novidades, permitindo a constante entrada de novos produtos no mercado internacional, situação que favorece aos países da América Latina que dispõem, em suas floras nativas, de espécies que são únicas no mundo e passiveis de aproveitamento racional com fins comerciais, favorecendo a competitividade do agronegócio marcado pela intensa competição de países economicamente mais fortes. Brasil e Argentina estão em uma zona de origem e diversidade de espécies com grande potencial ornamental (ex.: gêneros Alstroemeria, Calibrachoa, Petunia, Glandularia e familias Orchidaceae, Araceae, Bromeliaceae, Zingiberales, Cactaceae, etc), situação que lhes dão uma maior vantagem competitiva, pela disponibilidade de genes para obtenção de variedades mais adaptadas e tolerantes aos estresses bióticos e abióticos nos ambientes de cultivo.

É importante salientar que a América Latina tem historicamente contribuído para o desenvolvimento deste mercado pela incorporação de germoplasma de sua flora nativa nos programas de pre-melhoramento e melhoramento de empresas multinacionais. Prova disso são as numerosas espécies que podem ser encontradas em catálogos internacionais que têm uma base genética aportada de algum centro de origem ou distribuição latino-americana. Entretanto, os países da região não têm recebido nenhum tipo de benefício por este aporte. Os produtores locais devem pagar "royalties" pelo direito de comercializar variedades ornamentais, sendo Alstroemeria e Anthurium exemplos típicos. Esta é uma situação previsível em razão da carência de pesquisa e lentidão no desenvolvimento tecnológico.

Dentro deste contexto, é importante destacar que tanto a Argentina como o Brasil apresentam um denominador comum que é a grande quantidade de recursos fitogenéticos ornamentais e pouca quantidade de pesquisadores formados e agregados nesta temática, principalmente nas atividades de domesticação das espécies, propagação e melhoramento, para aproveitamento sustentável.

\section{SITUAÇÃO ATUAL}

Atualmente não existe uma rede de pesquisa em ornamentais entre instituições da América Latina, embora muitas ações estejam em andamento através projetos individualizados, interesses localizados e algumas ações de cooperação. Iniciativas como a dos cursos oferecidos pelo Centro Brasileiro-Argentino de Biotecnologia (CBAB/ $\mathrm{CABBIO)} \mathrm{mostram} \mathrm{ser} \mathrm{possível} \mathrm{a} \mathrm{união} \mathrm{de} \mathrm{esforços} \mathrm{entre}$ 
países para avanços de interesse comum, com a participação de pesquisadores de paises da América do Sul. O potencial das plantas ornamentais nativas como fonte de benefícios intangíveis e o ponto de convergência para a criação deste grupo de trabalho.

A situação esperada como resultado desta proposta é a formação de um grupo de intercambio de pesquisa e formacao de recursos humanos voltado para ações que avancem em estudos sobre as diversas areas da floricultura. Também se espera que outras iniciativas semelhantes sejam favorecidas, consolidando o grupo não apenas como instrumento capaz de contribuir para o desenvolvimento do agronegócio flores e plantas ornamentais na América Latina, mas também como elemento fomentador de novas iniciativas e a semente para a criacao de uma futura rede.

\section{JUSTIFICATIVA PARAA COOPERAÇÃO INTERNACIONAL}

Num mundo globalizado no qual a consolidação de grandes blocos comerciais como Nafta, Mercosul, tem sido objetivo dos governantes, percebe-se um esforço generalizado para se criar esta abordagem integracional. Neste contexto, inclui-se a intencao da formação de uma futura rede de pesquisa entre paises de um mesmo bloco, para união de esforços visando maximização de recursos voltados para objetivos comuns.

Do ponto de vista da pesquisa com plantas ornamentais constata-se que ha uma defasagem em relação a outras culturas agricolas, que só poderá ser superada com a união de esforços entre as instituições de pesquisa e ensino dos paises interessados no tema, uma vez que ações individuais esbarram nas limitações de recursos financeiros e humanos

A troca de informações possibilitara a rápida uniformização do conhecimento entre países, com nivelamento tecnológico entre os parceiros, fortalecendo com isto o setor produtivo, aumentando sua competitividade e promovendo o desenvolvimento harmonico do setor dentro do bloco.

PROGRAMA

\begin{tabular}{lll}
\hline Data & Assunto & Responsável \\
\hline 09 & Abertura, apresentação grupo & Dr. Alejandro S. Escandón \\
& Atividades desenvolvidos no Instituto de Floricultura I.N.T.A. & Ing. Agr. (M.Sci) Laura Bullrich \\
& Pesquisas com Floricultura na EMBRAPA-CE, Brasil & Dra. Ana Cecília R. de Castro \\
& Pesquisas com Floricultura na UFRPE, PE-Brasil & Dra. Vivian Loges \\
& Pesquisas com Floricultura no IAC-APTA, SP & Dr. Antonio F. C. Tombolato \\
& Apresentação SBFPO e ISHS & Dr. Antonio F. C. Tombolato e \\
& Projeto Plantas do Futuro, Brasil & Dra. Ana Cecília R. de Castro \\
& & Dr. Alejandro S. Escandón \\
& Visita a Ensaios de Campo del Instituto de Floricultura - INTA & Dra. Gabriela Facciuto \\
& &
\end{tabular}

\section{DISCUSSÕES}

Foram discutidos vários aspectos da integração da pesquisa em floricultura entre o Brasil e a Argentina como um primeiro passo para uma interação latino-americana, provavelmente através da criação de uma rede ou de uma associação. Outros países potenciais para esta ação seriam o Chile, a Bolívia, o México e a Colômbia, entre outros, cujos pesquisadores e professores da área deverão ser contactados para a exposição desses nossos objetivos.

Foram aventadas as possibilidades de intercâmbio para a formação de recursos humanos nos diversos níveis, como por exemplo para pós-graduação na Universidade Federal Rural de Pernambuco, no Instituto Agronômico, na Embrapa e na Universidade de Lomas de Zamora-INTA (mestrado em Floricultura), para estágios de treinamento e especialização e cursos em geral.

Haverá um maior esforço para promover a participação de ambos os países nos respectivos congressos de Floricultura e Plantas Ornamentais e outros encontros da área. Por ocasião desses congressos deverão estar programadas mesas redondas específicas para a discussão de projetos que fortalecam a integração BrasilArgentina. Entre os tópicos atualmente em destaque para discussão entre os países seriam as leis de proteção de cultivares e de acesso ao patrimônio genético.

Outra preocupação comum tem sido o método de avaliação qualitativo das publicações científicas da área 
da horticultura em geral. Muitos aspectos não são considerados no atual sistema de avaliação dos periódicos como por exemplo o valor nacional da pesquisa para os indicadores sócio-econômicos e ambientais.

$\mathrm{O}$ uso de recursos genéticos nativos de vegetais ornamentais são muitas vezes considerados apenas relevantes para divulgação local, nao sendo aceito ou de pouco interesse para revistas de maior impacto e de divulgaçao internacional. É importante ressaltar que alguns resultados destas áreas de pesquisa são referências para a ciência por décadas. A diversidade de espécies cultivadas, ou potenciais, na horticultura em geral requer longos anos de trabalho para a obtenção de resultados, principalmente com recursos genéticos e programas de melhoramento. $\mathrm{O}$ lançamento de uma variedade, por exemplo, e uma atividade primordial para a sobrevivência da atividade hortícola que de necessita frequentemente de novos materiais.

Constata-se que a maioria das revistas científicas na área de ciências agrárias foi requalificada para níveis inferiores no sistema de avaliação que prioriza o fator de impacto. Sao raras as publicações que permaneceram em um nível mais alto, no que se infere que os melhores resultados da pesquisa nacional devem ser publicados em revistas estrangeiras, em inglês. O resultado poderá ser um enfraquecimento das revistas e sociedades científicas nacionais. E evidente que vivemos um momento de privatização dos resultados da pesquisa em detrimento dos resultados de livre acesso. As revistas com maior fator de impacto cobram elevadas taxas e tem interesse em publicar artigos com produtos e atividades de maior valor econômico.

\section{RESULTADOS}

Como resultados das discussões foram definidas as seguintes propostas:

- Alinhamento de diretrizes para a pesquisa na área de recursos genéticos espécies vegetais ornamentais;

- Fomentar a criação de uma Rede ou Sociedade Brasileiro-
Argentina de Floricultura;

- Transformar a Revista Brasileira de Horticultura Ornamental em uma revista de maior atividade e abrangência na America Latina;

- Fomentar a preparação de projetos para editais internacionais para consolidar uma rede para uso e manutenção de recursos genéticos de espécies vegetais ornamentais;

- Discutir as leis de acesso ao patrimônio genético e de proteção de cultivares de cada país;

- Promover a interação e integração dos grupos de pesquisa, ensino e sociedades publicas e privadas de floricultura entre o Brasil e a Argentina com vistas a uma expansão para outros países da América Latina;

- Formar recursos humanos nas diferentes áreas da floricultura através de intercâmbio de especialistas, organização de cursos, seminários e grupos de trabalho; - Realizar estudos de competicao de cultivares regionais dos materiais selecionados das instituicoes interessadas, entre outras pesquisas;

- Conciliar a organização de eventos técnico-científicos congregando representantes de ambos países.

Certamente os esforcos da uniao Brasil e Argentina poderao sinergizar as atividades de pesquisa, promissoras para o progresso da ciencia da horticultura ornamental.

\section{AGRADECIMENTOS}

Ao Instituto de Floricultura - INTA Castelar, Embrapa Agroindustria Tropical,Instituto Agronomico, Universidade Federal Rural de Pernambuco - PPGEA, CNPq.

Alejandro S. Escandón (INTA)

Ana Cecília R. de Castro (EMBRAPA-CNPAT) Antonio Fernando C. Tombolato (IAC)

Daniel Morisigue (INTA)

Gabriela Facciuto (INTA)

Laura Bullrich (INTA)

Vivian Loges (UFRPE) 